\title{
Turbulence Processes in the Stable Marine Atmospheric Boundary Layer
}

\author{
Clive E. Dorman \\ Scripps Institution of Oceanography \\ 9500 Gilman Drive, La Jolla, CA 92093-0209 \\ phone: (858)534-7863 fax: (858)534-0300 email: clive@ coast.ucsd.edu \\ Ian M. Brooks \\ Scripps Institution of Oceanography \\ 9500 Gilman Drive, La Jolla, CA 92093-0209 \\ Phone: (858)534-4333 fax: (858)534-0300 email: ibrooks@ucsd.edu
}

Award Number: N00014-01-1-0258

\section{LONG-TERM GOALS}

The long-term goals of this study are to improve our understanding of turbulence processes within the stable marine atmospheric boundary layer in spatially heterogeneous coastal environments with the aim of improving numerical representation of such environments.

\section{OBJECTIVES}

The study has two distinct objectives. The first is the study of the evolving turbulence structure of the stable boundary layer as the mesoscale flow rounds a coastal headland and forms an expansion fan in which the flow accelerates and the boundary layer collapses. The region around the headland is one of extreme spatial heterogeneity - there are large changes in wind speed an order of magnitude increase in the surface wind stress, and boundary layer depth decreases by a factor of about 5. A large surface wind-stress curl drives enhanced upwelling of cold water creating a cold pool just downwind of major headlands; this increases the local stability further modifying the overlying boundary layer structure.

The second objective is to characterize the entrainment zone structure at the top of the boundary layer. Previous studies of entrainment zone structure have focused almost entirely on convective conditions; this is the first extensive study of entrainment zone structure for the stable marine boundary layer.

\section{APPROACH}

An extensive set of aircraft measurements from the Coastal Waves 96 (CW96) field campaign are being utilized for this study. Turbulence measurements from straight and level flight legs within the surface layer $(30 \mathrm{~m})$ define the surface forcing; measurements from extensive series of sawtooth profiles extending from approximately $15 \mathrm{~m}$ to above the inversion are used to derive both the mean and turbulent vertical structure following the approach of Tjernström (1993). The observations are being studied alongside numerical simulations being conducted by Michael Tjernström and Stefan Söderberg of Stockholm University, Sweden. Analysis of the aircraft data and integration of results from the modeling study is being undertaken by Ian Brooks at SIO. 


\section{Report Documentation Page}

Form Approved

OMB No. 0704-0188

Public reporting burden for the collection of information is estimated to average 1 hour per response, including the time for reviewing instructions, searching existing data sources, gathering and maintaining the data needed, and completing and reviewing the collection of information. Send comments regarding this burden estimate or any other aspect of this collection of information,

including suggestions for reducing this burden, to Washington Headquarters Services, Directorate for Information Operations and Reports, 1215 Jefferson Davis Highway, Suite 1204, Arlington

VA 22202-4302. Respondents should be aware that notwithstanding any other provision of law, no person shall be subject to a penalty for failing to comply with a collection of information if it

does not display a currently valid OMB control number.

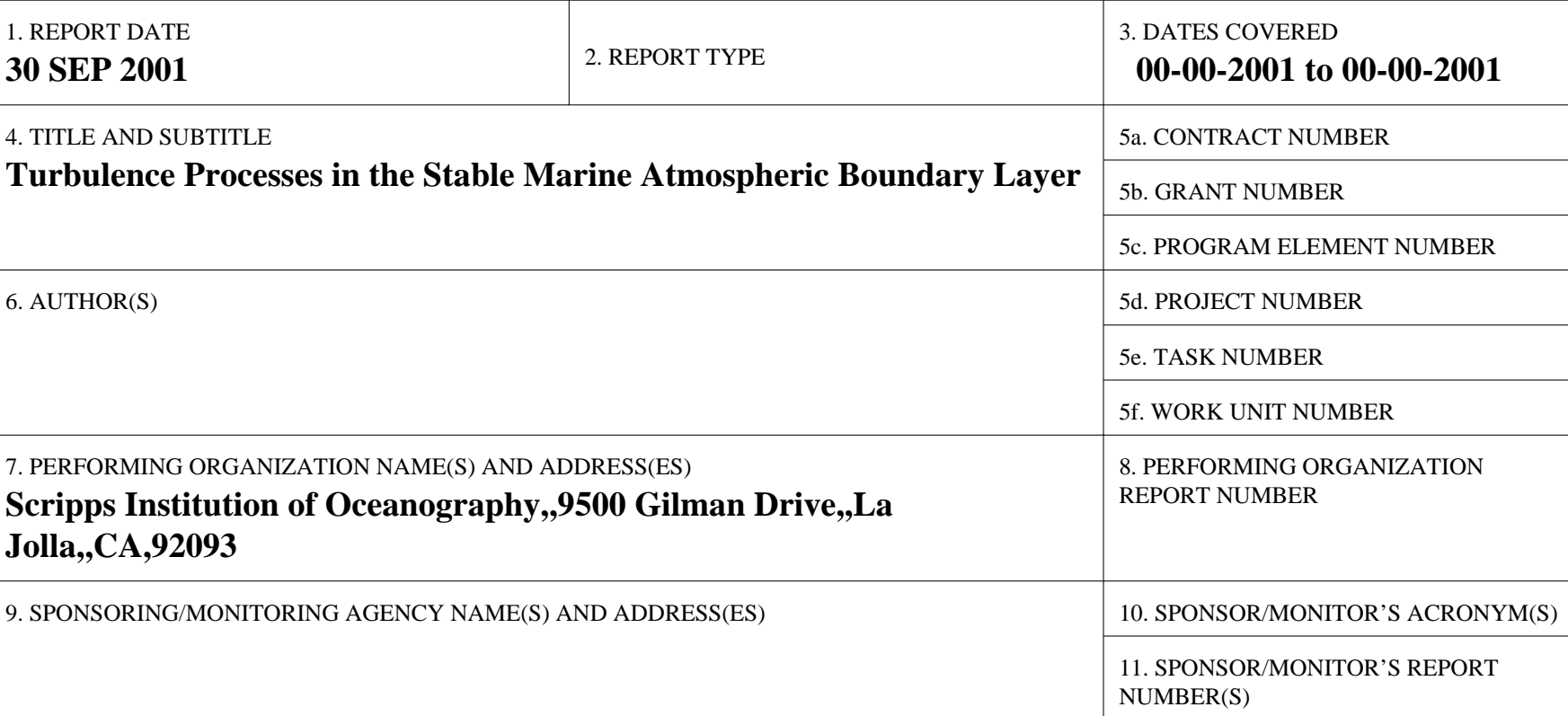

12. DISTRIBUTION/AVAILABILITY STATEMENT

Approved for public release; distribution unlimited

13. SUPPLEMENTARY NOTES

14. ABSTRACT

The long-term goals of this study are to improve our understanding of turbulence processes within the stable marine atmospheric boundary layer in spatially heterogeneous coastal environments with the aim of improving numerical representation of such environments.

15. SUBJECT TERMS

16. SECURITY CLASSIFICATION OF:

\begin{tabular}{|c|c|c|}
\hline $\begin{array}{c}\text { a. REPORT } \\
\text { unclassified }\end{array}$ & $\begin{array}{c}\text { b. ABSTRACT } \\
\text { unclassified }\end{array}$ & $\begin{array}{c}\text { c. THIS PAGE } \\
\text { unclassified }\end{array}$
\end{tabular}

\begin{tabular}{|c|c|l|}
$\begin{array}{c}\text { 17. LIMITATION OF } \\
\text { ABSTRACT }\end{array}$ & $\begin{array}{c}\text { 18. NUMBER } \\
\text { OF PAGES }\end{array}$ & 19a. NAME OF \\
Same as & $\mathbf{5}$ & \\
Report (SARSIBLE PERSON & & \\
\hline
\end{tabular}


The study of entrainment zone structure utilizes data from the NCAR SABL lidar system flown during CW96; this provides exceptionally high resolution data with which to determine the small-scale structure of the entrainment zone $-3.75 \mathrm{~m}$ in the vertical by approximately $5 \mathrm{~m}$ in the horizontal. Detection of cloud and boundary layer top is performed using a wavelet-based algorithm (Davis et al. 2000). The statistical properties of the entrainment zone will be compared with those for convective conditions available in the literature. All analysis is being conducted by Ian Brooks.

\section{WORK COMPLETED}

The aircraft turbulence data has been processed and comparisons of surface layer turbulence fields with those from both simple bulk parameterizations and mesoscale numerical models undertaken. The vertical turbulence structure has been analyzed from the perspective of local similarity theory. Model simulations have been completed by our collaborators at Stockholm University, but due to the commitments of field work these have not yet been analyzed and compared with the observations. This work will proceed over the next few months. Two papers will be presented at the $4^{\text {th }}$ AMS Conference on Coastal Atmospheric and Oceanic Prediction and Processes in Florida, November 2001 (Brooks et al. 2001; Söderberg et al. 2001)

As an offshoot of the central study of turbulence structure, the effect of the spatial variability of surface layer turbulence forcing on the so-called surface evaporation radar duct has been assessed - the duct depth was estimated from a bulk parameterization and the spatial distribution compared with that of the directly measured turbulence forcing. The results have recently been published in Geophysical Research Letters (Brooks 2001).

The analysis of lidar data to determine entrainment zone structure is challenging - in stable conditions the top of the boundary layer is less well defined than for a well-mixed convective layer, making the design of an effective algorithm for automated processing of the lidar data more difficult. We have settled on a wavelet based approach, which provides a more robust approach than simply assessing the local gradient of the lidar backscatter as proposed in our original proposal. Processing of the lidar data for the cloud capped cases is complete, and analysis in progresses. Further refinement of the algorithm for the more variable cloud-free cases is underway.

\section{RESULTS}

Analysis is not yet complete and thus the available results are limited at this time. A significant preliminary result of the analysis of the turbulence structure of the stable boundary layer is the applicability of local similarity scaling within highly heterogeneous environments. Figure 1 shows the scaled vertical velocity for the flight on June $7^{\text {th }}$, this displays a clear functional dependence on stability - the scaled velocity increases with increasing stability in agreement with the observations of Shao and Hacker (1990), but in contradiction to Nieuwstadt's (1984) original study which suggested that the scaled quantities should approach constant values with increasing stability. Panel (b) shows the results for the whole flight, bin averaged by stability, along with individual estimates from within the expansion fan - these display excellent agreement indicating that the scaling applies even through the dramatic changes in mean structure and turbulence forcing as the flow enters the expansion fan. 

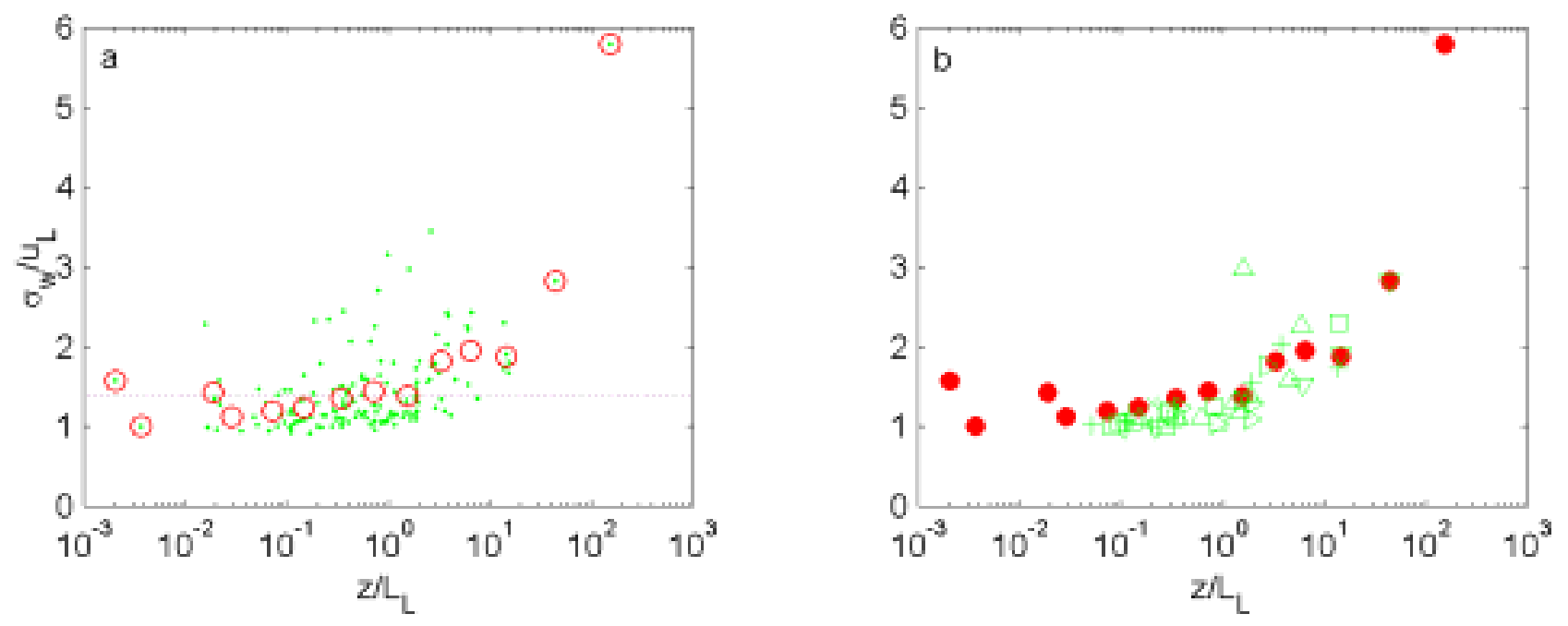

Figure 1. Local similarity scaling of the standard deviation of vertical velocity plotted against the local stability parameter, $z / L_{L}$ : (a) green dots are individual estimates of the scaled vertical velocity for the whole flight; red circles are the same data bin-averaged by stability, the dotted line indicates the constant value of 1.4 suggested by Nieuwstadt; (b) red circles are the bin averaged results for the whole flight, green symbols are individual estimates from within the expansion fan only. Excellent agreement is observed between the results in-fan and those for the flight as a whole.

The assessment of the relationship between the spatial variability of surface turbulence forcing and the surface evaporation duct determined that there is a strong correlation between the two, and that the duct depth varies by a significant amount over distances of tens of kilometers in the vicinity of the coastal headland. These results highlight a region which the spatial variability of the duct may be important for operational assessment of radar propagation conditions.

Results from the entrainment zone study are not yet available.

\section{IMPACT/APPLICATIONS}

The finding that local similarity scaling can be applied to spatially highly heterogeneous conditions may be applied to numerical modeling studies where local similarity can be used to provide a closure for turbulence parameterization schemes.

The finding of significant variability in surface evaporation duct depth emphasizes the need to assess such variability when determining radar propagation within the coastal zone. This is an important consideration for operational applications.

\section{TRANSITIONS}

These results are not yet published, and thus not yet being utilized by other researchers. 


\section{RELATED PROJECTS}

An NSF funded project, DYCOMS-II, investigating entrainment at the top of cloud capped marine boundary layers has recently completed its measurement program off the coast of California. This study focuses on nocturnal, convective conditions. Comparison of results and possible collaboration on analysis of lidar data from DYCOMS-II is being discussed with the PI Bjorn Stevens.

\section{REFERENCES}

Davis, K. J., N. Gamage, C. R. Hagelberg, C. Kiemle, D. H. Lenschow, and P. P. Sullivan, 2000: An objective method for deriving atmospheric structure from airborne lidar observations. J. Atmos. Oceanic. Technol., 17, 1455-1468.

Nieuwstadt, F. T. M., 1984: The turbulent structure of the stable, nocturnal boundary layer, J. Atmos. Sci. 41, 2202-2216.

Shao, Y., and Hacker, J. M., 1990: Local similarity relationships in a horizontally inhomogeneous boundary layer, Bound.-Layer. Met., 52, 17-40.

Tjernström, M., 1993: Turbulence length scales in stably stratified free shear flow analyzed from slant aircraft profiles, J. Appl. Met., 32, 948-963.

\section{PUBLICATIONS}

Brooks, I. M., 2001: Air-sea interaction and the spatial variability of surface evaporation ducts in a coastal environment. Geophys. Res. Letters., 28, 10, 2009-2012.

Brooks I. M., S. Söderberg, and M. Tjernström 2001: The turbulence structure of the stable atmospheric boundary layer around a coastal headland: I. Aircraft observations. Proceedings of the AMS $4^{\text {th }}$ Conference on Coastal Atmospheric and Oceanic Prediction and Processes. In Press

Söderberg, S., I. M. Brooks, and M. Tjernström. 2001: The turbulence structure of the stable atmospheric boundary layer around a coastal headland: II. Modelling results. Proceedings of the AMS $4^{\text {th }}$ Conference on Coastal Atmospheric and Oceanic Prediction and Processes, In Press. 